\title{
Roots of Math in Preschool Play Activities: Gender Still Does Matter
}

\author{
I. Smetackova
}

\begin{abstract}
The main activity in the preschool period is play, which stimulates development in cognitive, social, motor and identity areas. Play and toys contribute to gender socialisation by the means of play, children form and present their notion of gender structure of the society and their position in it. The gender polarization of play activities brings long-term consequences for children performance, achievements and interests in different areas. One of the effects can be the quit low women's inclination toward mathematical and technical fields in adolescence and adulthood (despite of more equal talents for such areas distributed among girls and boys). Therefore it is important to pay attention to early childhood experience with toys and play activities associated with math and construction. Paper presents the study including 453 preschool boys and girls who were observed during playing and interviewed. The real preference of toys, verbalized preference of toys and gender labeling of toys were compared. The results show that preschool children consider toys as deep gendered artefacts. The gender borderline creates cars and dolls. The ways how children play with those toys are discussed with regard to development of mathematical and technical skills.
\end{abstract}

Index Terms-Toys, gender, maths, preschool age.

\section{INTRODUCTION}

Research studies conducted across cultures and psychological paradigms agree that play is a key and irreplaceable activity in early childhood. Play stimulates the child's development in many areas, in particular perceptive, cognitive, motor and social [1], [2]. During the play, children extend their knowledge about certain domains and develop specific skills. Play also facilitates development of the child's personality and identity. By playing, children construct the concept of social reality and their place in it, and consequently, they prefer certain types of activities, in which they gradually improve their performance and which they start using to form their personal identity [3], [4].

Children's play takes place in a specific culture where a number of explicit or implicit mechanisms influence the frequency, content and organization of the child play [5]. The way how the society is structured by ethnicity or gender is reflected in the offer of toys and in directing specific groups of children towards certain types of play by the adults. The stronger the gender polarization of the society, the more cultural artefacts, including toys, are associated with either femininity or masculinity.

Manuscript received July 1, 2014; revised September 10, 2014. This work was supported by the Czech Science Foundation, P407/11/1740.

I. Smetackova is with the Department of Psychology, Faculty of Education, Charles University, Czech Republic. Contact: Rettigove 4, 110 00 Prague 1, Czech Republic (e-mail: irena.smetackova@ pedf.cuni.cz).
Toys are material objects, but they are also representations of social and cultural practices [6]. It brings two impacts. Firstly, children learn through play the concepts of femininity and masculinity (what covers being a girl/woman and a boy/man). Secondly, children are engaged in certain play activities, associated with their gender. Toys thus have a double role - they are means of expressing the child's gender and they are at the same time a tool of gender socialization [1]. In other words, toys serve the purpose of both forming and performing the gender identity.

Many western studies show that toys featuring an element of action, technical or mechanical construction are considered appropriate for boys and are also preferred by boys are, while toys based on care and aesthetics are associated with girls [3]. These associations are based on gender stereotypes and thus have socio-cultural nature. Recent study of spontaneous play in preschool age found that girls significantly preferred pretend play (f.e. play "on flower shop 'or' on medical doctors") while boys favored constructive play as LEGO [7].

There are long-term consequences in many ways of those gender differences in play offers and play activities in preschool age. One effect implies the deeper boys' interest in mathematical and technical field which is followed with better achievements in those areas and higher subjective competence. Longitudinal study made by Wolfgang et al. [8] shows the high correlation between playing with LEGO (as typical constructive activity in age 3 and 4) and math performance in seventh grade and later. Moreover, the consequences can be neurobiological as well [9]. Regarding the plasticity of brain, the longtime and frequent exposition of certain play activity can bring the change in neurological functioning. Thus, specific brain center (f.e. responsible for visual-spatial abilities) can be developed more than others [1].

The decades of research on gender differences in children play show the stable results: there are two basic sources influencing the children preferences of toys and play activities. First source includes cognitive, motor and social developmental patterns based in maturation. Second source includes all socio-cultural factors [1]. Both sources blend together, thus their distinction is more hypothetical. In this paper the attention is paid to socio-cultural factors as gender roles and gender labeling of toys and play activities [5]. Children gain information about gender labeling mostly through adults support (f.e. parents and teachers offer children some toys and react to children spontaneous choices) and through peer pressure.

Maccoby [2] and others [10] show how early (in age of 3 years) children start to prefer spending time with peers of 
same gender which lasts during whole preschool period. The reason probably is that children are in this time intensively building their knowledge about gender and seeking for their own place in social reality. They find helpful to belong to the group of children who are similar to them. However, gender segregation makes the deeper gender polarization in activities, including plays.

Research studies agree that children acquire the basic concept of gender very well by the age of between 2 and 3 years [11]. Already at this early age they are able to define masculinity and femininity by their main features and they understand the differences. By the age of three years, children distinguish between males and females, and associate one gender category with certain objects (e.g. cars-men). During the preschool period, their knowledge of gender roles further develops reaching its peak upon entering the early primary school age and the formed gender schemas remain relatively unchanged also in the subsequent periods [4], [11].

The primary knowledge of gender is very rigid, presuming polarization and universality. From the cognitive perspective, children are not able to accept deviations from the notions of masculinity and femininity [12]. Children at the age of 4-5 years are not able to consider counterstereotypical information. If they are asked to make judgement about other children's toy preferences, they apply gender stereotypes, which associate certain groups of toys with masculinity and others with femininity not taking into account the situational information. For instance, if a boy mentions he likes to play with dolls, other children, when asked what type of toys the boy prefers, will insist he prefers cars [5].

Flexibility, i.e. the ability to take into account inaccuracy of generalised gender schemas, as a result of which children are able to accept the cases of crossing gender boundaries, develops later. During the preschool period, the flexibility first decreases reaching its lowest level at the age of between 5 and 7 years, after which it increases and reaches its highest level at the age of between 10 and 12 years [11], [12].

Cognitive processes, attitudes and behavior are influenced by gender schemas [12]. Preschool children process information consistent with dominant gender schemas more easily and thus they prefer gender-stereotypical activities [5], [3]. Gender schemas facilitate the encoding and retrieval of information, support boys and girls to pay attention to and to be motivated for different objects and activities [11], [12]. Finally, gender schemas work as a platform for developing a polarized gender identity [10].

After the cognitive flexibility increases, children are able to explicitly reject gender stereotypes as inaccurate or not reflecting reality. However, mental flexibility does not necessary brings a change in behavior, in particular if behavioral manifestations follow automatically activated stereotypes. Banse a Gawronski found there is no direct link between gender knowledge, gender flexibility and manifestation of gender, therefore increased mental flexibility does not result in higher behavioral flexibility [11]. However, research conducted by Banerjee and Lintern [13] showed that children with more rigid schemas behave and present themselves with higher gender stereotype conformity. It can be assumed from the above that gender stereotype flexibility is a necessary, but not sufficient condition for reaching higher flexibility in behavioral manifestations.

\section{MeTHODOLOGY}

Many studies since 70's examined boys' and girls' preferences of toys. For preschool children the results show that children distinguish between toys associated with masculinity and femininity and they favor the toys associated with their gender. Present studies have not yet fully explained the relationship between mental rigidity or flexibility and real manifestations of gender stereotyping.

When studying the play of preschool children the following question can be posed: What is the relationship between children's gender concepts associated with toys, personal toy preferences and the real choice of toys? It is interesting to study the degree of rigidity and flexibility in all three areas (mental stereotyping, personal preferences and real preferences of toys) and to search for mutual relationships.

With regard to building-up of mathematical ability and interest, the study asks supplemental question: What is the difference between toys preferred by preschool girls and boys in terms of numeration, construction and visualisation?

\section{A. Sample}

The study included 453 children, out of which 230 girls and 223 boys. All children attended nursery schools. The age of children included in the sample ranged between 3 and 7.7 years with the average age reaching $5.13(s d=1.05)$. The average age of girls was $5.04(s d=1.05)$ and the average age of boys was $5.22(s d=1.05)$. This age difference is not statistically significant.

Observations were conducted in the total of 82 nursery schools throughout the Czech Republic. Nursery schools must follow the national curriculum guidance ensuring that all children are exposed to the same educational framework and approach. The national curriculum defines as a main goal the complex child development, however the elimination of gender stereotypes is not included explicitly. Because Czech teachers are not trained yet in gender equality, they can behave in stereotypical way and support children in gender stereotyping and polarizing.

Nursery schools in the Czech Republic are intended for children between three and six years of age, however attendance is not compulsory (the compulsory school attendance age is six years). The proportion of children attending nursery schools in individual age categories ranges between 28\% (3-year-olds) and 90\% (5-year-olds). Children at the age of six years and more attending nursery schools are children that were granted postponement of compulsory school attendance and they represent $21 \%$.

\section{B. Procedures}

Data were collected by the team of trained assistants who followed the precise instructions. All of them were pre-gradual students in the field of preschool pedagogy and spent at least a week in each school. The basic methods were the observation and the short individual follow-up interview.

Only free, spontaneous play behavior in the nursery school 
environment was observed covering the period of one week. During the observation period, types of play activities in which children voluntarily engaged were recorded. The three most frequent activities were subsequently recorded in the individual sheet for each child.

Approximately one week after the observation, an interview with each child including the following five questions was conducted:

1) What toys do you think girls play with?

2) What toys do you think boys play with?

3) Are there any toys which the girls are not supposed to play with? Why?

4) Are there any toys which the boys are not supposed to play with? Why?

5) What is your favorite toy?

The questions were asked in an undisturbed setting without the presence of other children to ensure that the child is not influenced by replies of peers. The answers were written down in the individual sheets.

All facts were recorded during observations and interviews without classification or sorting. In total 4,522 records were collected which were divided into six groups according to the tool used, i.e. the observation and the five questions asked during the interviews. For each child it was possible to record up to three different data items in each of the groups (e.g. the child could specify up to three favorite toys). The data were analyzed and new variables reflecting the dominant answer in each group were created. A part of the results thus provides information about the dominant answer provided and a part gives information about the variability all obtained answers (the difference is always explicitly mentioned).

All data were collected directly using the prepared data collection sheets. Subsequently, the collected data were converted into the digital format. No classification system that might influence the collection of data was used during data collection. The data were classified after collecting a complete set of data and the classification was based on the initial analysis. The created classification key contained 42 categories of different types of toys and play activities mentioned by children during the interviews. After classification and conversion into electronic format, the data were further analyzed and, as a result of this analysis, the list of classification categories was narrowed to 18 by aggregating similar types of toys into one category (e.g. cars and slot car racing tracks, dolls and Barbie, painting and paper cutting etc.). Reduced typology includes following play activities and toys:

1) Dolls (baby doll, Barbie etc.).

2) Cars and transportation vehicles.

3) Construction, manual dexterity and technical plays.

4) Household plays, cleaning, cooking.

5) Arms and combat.

6) Play figures and animals (horses, fairies, etc.).

7) Action figures (transformers, etc.).

8) Board games (pairs, cards, etc.).

9) Creativity (drawing, modeling, etc.).

10) Sport (running, throwing, etc.).

11) Books, computer.

12) Imaginative plays (hospital, shopping, etc.).

13) Other toys (e.g. clothes pegs, flower pot, etc.).
14) Dangerous toys (e.g. matches, etc.).

15) Appearance modification and change.

16) Girls' toys, toys for girls.

17) Boys' toys, toys for boys.

18) Other toys, without limitations.

The classification code was based primarily on children's answers. However, it is necessary to consider the limits which come from dichotomous questions (children were asked to distinguish between girls and boys). It can probably make the bigger difference in labeling of toys then it exists in "real" settings.

After developing the complete version, the classification code was applied to all answers obtained during the interviews and also to the observations. As follows from the logic of the classification, categories 16-18 could not be used during the observations because they represent generalized descriptions of the words used by the children themselves. In reply to the question what toys are boys not supposed to play with some of the children replied "with toys for girls" or "for boys". Out of the total number of answers obtained during the interviews $(3,606) 3.3 \%$ used explicit gender polarized categories. Even though this number might seem small, the explicitness of these answers suggests that gender classification is not entirely unfamiliar to children and we can expect that also other children's answers were based on implicit association of toys with a specific gender. It means that all other children mentioning specific examples of toys might also consider their association with one gender, but they did not explicitly describe them as toys for girls or boys.

\section{RESULTS}

This chapter presents main results of the study. As was described, the research was focused on three areas (verbalized mental stereotyping about toys in general, verbalized personal preferences of toys and real preferences during spontaneous play) and relationships among them. Each area will be discussed separately.

\section{Real PREFERENCES IN SPONTANEOUS Play}

In total there were 916 spontaneous play activities observed. It is on the average two activities per one child. Only most vivid activities in a week observed period were recorded and if a child engaged only in one type of play activity, it was recorded as one occurrence.

There is significant difference between boys' and girls' plays. Boys play significantly more often with construction sets and toy cars, girls on the other hand with dolls, figures, or they engage in painting and modeling. The difference is statistically significant, $x^{2}(13, n=391)=208.1, p<0.01$. The most frequent play activities are shown on Table I.

TABLE I: DOMINANT TYPES OF SPONTANEOUS PLAY

\begin{tabular}{lll}
\hline \hline Toys, plays & Girls & Boys \\
\hline Construction & $12.4 \%$ & $50.0 \%$ \\
Dolls & $23.8 \%$ & $2.8 \%$ \\
Creative activities & $24.9 \%$ & $1.6 \%$ \\
Cars & $1.6 \%$ & $26.8 \%$ \\
\hline \hline
\end{tabular}


Also other analyses show that children strictly attribute dolls to girls and transportation vehicles to boys. When focusing only on these two types of toys, a significant difference can be observed. Dominant playing with dolls was observed in $31 \%$ of girls, but only $2.6 \%$ of girls played with toy cars. Among boys, $39.3 \%$ chose playing with cars as the dominant type of play, and only $3.6 \%$ played with dolls. This difference is statistically significant, $x^{2}(1, n=194)=163.24$, $p<0.01$. Other children ( $66 \%$ of girls and $57 \%$ of boys) played solely with other types of toys then cars and dolls.

Dominant types of play activities observed change with age both in the girls' group, $x^{2}(40, n=192)=68.63, p<0.01$ and in the boys' group, $x^{2}(48, n=197)=90.19, p<0.01$. In the girls' group, interest in dolls slightly decreases - whilst among 3-year-olds $33 \%$ of girls played with dolls, among 6 -year-olds it was $18 \%$. The decline in the interest in dolls can be shown also on the negative correlation between age and the choice of dolls ( $r=-0.142, p<0.05)$. On the other hand, popularity of painting, modeling and paper cutting increases with age in the girls' group. Among 3-year-olds these activities were observed during spontaneous play only in $4 \%$, whilst among 6-year-olds it was $33 \%$. When interpreting these findings, it is of course necessary to take into account that younger children may not be provided the conditions for manual and creative activities by nursery school teachers during the time reserved for free play. In the boys' group, the occurrence of playing with toy cars decreases with age. Among 3-year-olds $42 \%$ played with cars, whilst among 6 -year-olds it was $15 \%$. This is confirmed also by negative correlation $(r=-0.27, p<0.01)$. On the other hand, the proportion of boys playing with technical and construction toys grows from $17 \%$ in 3 -year-olds to $60 \%$ in 6-year-olds.

\section{VERBALIZED STEREOTYPING ABOUT TOYS}

\section{A. Toys Associated with Girls}

In other questions during the interviews the children were asked what toys do girls play with and what toys do boys play with in their opinion. Children probably based the answers on their own experience from a peer group, but also on generalised concepts which they may have acquired from their surroundings. The interviews did not allow to differentiate between these two sources of opinion.

According to children's opinion, two most frequently mentioned types of toys with which girls play most often are dolls and fairy figures or animal figures. More than $60 \%$ of children agreed that girls predominantly play with various types of dolls. Out of this, Barbie doll accounts for $8 \%$ and baby doll for $10 \%$. Boys consider dolls to be a typical girls' toy more frequently than girls (63\% vs. $58 \%)$, however the difference is not statistically significant. In spite of some partial differences, it can be stated that both groups share similar ideas about toys with which girls play with.

No significant differences in the structure of answers were observed between children of different ages. However, in the case of the most frequent reply (dolls), correlation with age was observed in the boys' group. With increasing age, boys mentioned more often dolls as the toys with which the girls play with $(r=0.239, p<0.01)$. This means that the schema of femininity is more narrow in older boys. As the observations showed, playing with dolls becomes less frequent among older girls, therefore the boys' opinion is not primarily based on seeing their girl peers playing with dolls more often.

The question about dominant toy was supplemented by a question asking what toys should in children's opinion girls not play with. Children mentioned most frequently as inappropriate toys for girls: cars, arms and "boys' toys". Cars and transportation vehicles are the most rejected types of toys mentioned by $45 \%$ of girls and $40 \%$ of boys. The proportion of children sharing this opinion was similar in all age groups.

The question was asked as an open question, i.e. the children had the opportunity to say there are no such toys. For this purpose, the classification code included the category "all toys without limitations". In the replies to the first question this category was chosen by only $1.5 \%$ of children (i.e. they stated that girls play with all types of toys, and therefore no toy can be called the toy most frequently played with by girls). In reply to a negatively posed question, which asked about what toys are in children's opinion inappropriate for girls, the occurrence of this type of answer increased up to $11 \%$ in girls and $9 \%$ in boys. A relatively large group of children therefore rejects the notion that there are any play activities not compatible with femininity.

\section{B. Toys Associated with Boys}

Another pair of questions looked for toys associated with masculinity. Children were asked what toys in their opinion do boys most frequently play with. Most frequently mentioned types of play activities are: cars, arms and constructions.

Similarly as in the case of the question relating to girls, more than one half of the children agreed on one type of toy. In the case of boys, this type of toy is cars and other transportation vehicles, which were mentioned by $60.5 \%$ of girls and $53.1 \%$ of boys. Almost $20 \%$ boys and girls see as most frequent toys, which boys play with, different kinds of tools, wooden or plastic bricks and construction sets as Lego. These toys involve manipulation with objects of technical nature. The answers were analyzed according to children age, but no significant differences were observed neither in the boys or the girls sub-groups. The opinion about what toys are dominantly used by boys is therefore similar across the entire observed population.

Later children were asked if there exist any toys which boys should not play with. More than one half of children mentioned dolls as toys that are not inappropriate for boys. Based on the analysis of the replies to the question about what toys do girls play with, dolls can be identified as the most typical girls' toy. It follows from the above that we can combine the category of dolls with the category of toys specifically described as girls' toys. According to almost $2 / 3$ of children, "girls' toys" are implicitly or explicitly considered inappropriate for boys.

\section{VERBALIZED PERSONAL PREFERRETION OF TOYS}

The last question within the interview was what toy children themselves preferred to play with. Children could appoint three favorite toys or play activities. Among girls, the 
most preferred toys are clearly dolls and also toys animals and figures, which were mentioned by $67 \%$ of girls. The boys preferred most often cars, construction sets and combat plays. These four groups represent $86 \%$ of preferred choices among boys. There were significant differences between replies provided by girls and boys, $x^{2}(14, n=451)=293.6, p<0.01$.

Girls' choices of favorite toys cover a slightly wider range of toys in comparison to the boys' choices. In the girls' group, $90 \%$ of answers were covered by a group of 7 types of toys, while in the boys' group it was only 5 types of toys. In both groups the diversity of choices grows with age (up to 10 types of toys in the girls' group, but only up to 6 types of toys in the boys' group). The diversity of answers provided by boys is smaller in all age sub-groups.

The popularity of individual types of toys changes with children's age. In the whole sample, there were significant differences between answers provided by children of different ages, $x^{2}(56, n=449)=78.25, p<0.05$. In the boys' sub-group, the difference between age groups was confirmed, but in the girls' sub-group it was insignificant. In the boys' group, the popularity of several types of toys dropped when comparing the answers provided by 3-year-olds and 6 -year-olds - cars (63\% vs. $28 \%$ ), animal toys and figures (13\% vs. $4 \%$ ). On the other hand the popularity of other toys increased with age - construction toys (19\% vs. 27\%) and toy weapons (9\% vs. $20 \%$ ). $43 \%$ of 3 -year-old girls mentioned dolls as their most favorite toys with the preference dropping to $28 \%$ among 6-year-old girls. Figures and toy animals were the most favorite toy for $50 \%$ of 3 -year-old girls, but the preference dropped to only $39 \%$ among 6-year-old girls.

Children prefer mainly toys that correspond with their gender. This is obvious not only from the aggregate data suggesting that cars and construction sets are the most favorite boys' toys, but also the children generally agree that boys play with these toys most frequently and that girls are not supposed to play with them (specifically cars). Analyses also showed that dolls, figures or animals are toys preferred by girls and, at the same time, dolls are considered as toys appropriate for girls and inappropriate for boys. This linkage can be confirmed also by the analysis of specific answers. For instance, $82 \%$ out of 56 girls totally preferring dolls consider dolls to be girls' toys and according to $79 \%$ out of 66 boys totally preferring cars consider cars to be boys' toys. It is probable that children prefer toys that are in agreement with the schema of the gender category they belong to [5]. However, in order to stay in agreement with their gender schema even in the cases when they prefer other toys, they adapt to their own concept of toys classification accordingly. For instance $79 \%$ out of 14 girls for which the favorite toys are cars and construction sets mentioned these toys as toys with which girls play.

Toys identified by children as their personal favorites were subsequently compared to toys with which the children were observed to play during free play. The analysis of dominant types of play (i.e. the first choice) showed that in real play children prefer the same toys as they prefer on the level of their opinion, even though the strength of preference differs. $34 \%$ of girls expressed their preference to play with dolls and to play household plays and $36 \%$ played with these toys in practice. Playing with animals and figures was mentioned as the preferred type of play by $37 \%$ of girls and it was observed in practice only in $12 \%$ of them. The boys expressed highest preference for construction sets (38\%) and in reality as much as $50 \%$ of them played with these toys. Playing with cars was mentioned as the preferred type of play by $24 \%$ of boys and $27 \%$ of boys played with cars in reality. The biggest difference was observed in the case of combat plays which were mentioned as preferred by $24 \%$ of boys, but only $5 \%$ of boys played with combat toys in reality.

If we compare the top three toys mentioned as preferred during the interviews with the choice in practice, the agreement was observed in 234 children, i.e. $51.4 \%$ (when taking into account only one toy mentioned as the most preferred one, the rate of agreement was $22 \%$ ). This means that approximately one half of children were actually observed playing with the type of toy they mentioned as their favorite in an interview taking place after some time. The remaining half of children play with other toys than those they identified as their favorites in the interview. The absence of agreement suggests that mental concepts and behavioral manifestations are not in direct agreement in children. However, there can be also simple pragmatic explanations such as changing children's opinions (the delay between the observation and the interview was approximately one week) or the narrow choice of toys available in the nursery school.

Cars and construction sets were most frequently mentioned as toys appropriate for boys; dolls, figures and animals were most frequently mentioned as toys appropriate for girls. If we aggregate these toy categories taking into account all answers (i.e. not only the first, dominant answer) provided by children in reply to the question asking about their favorite toy and also toys observed during free play, both the preference rate and the real use rate of these toys increase. The relevant data are presented in Table II. Table shows that both in their expressed preferences and in their behavior both groups strongly focus on toys associated with their gender category.

TABLE II: DOMINANT TYPES OF PREFERRED AND REAL PLAY

\begin{tabular}{lcccc}
\hline \hline Toys, plays & \multicolumn{2}{c}{ Preferred play } & \multicolumn{2}{c}{ Observed real play } \\
\hline \hline & Girls & Boys & Girls & Boys \\
\hline Cars and construction & $17.8 \%$ & $93.3 . \%$ & $32.9 \%$ & $100 \%$ \\
Dolls and figures & $100 \%$ & $10.3 \%$ & $67.8 \%$ & $10.3 \%$ \\
\hline \hline
\end{tabular}

The table also suggests there is a different relationship between preferences and behavior in boys and girls. While boys in comparison to their expressed preferences played more with "boys' toys", the observations of girls suggest the opposite (all girls prefer "girls' toys", but only 2/3 played with them). It can be deduced from the aforementioned that girls are very well aware of gender expectations, but they conform to them less in their real behavior. Another finding relates to the higher proportion of girls expressing preference of "boys' toys". It is interesting that among girls, the real use of these toys was higher than the declared preference. This is in agreement with the aforementioned interpretation according to which girls follow less the expectations imposed by gender roles, but they are aware of them.

The agreement between the toy indicated as preferred and the toy used in real play occurred more often in boys (57.6\%) 
than in girls $(45.5 \%)$. This difference is statistically significant, $x^{2}(1, n=455)=6.78, p<0.05$. Among girls, the agreement was highest in the case of dolls (40\%) and figures or animals $(27 \%)$, among boys, it was construction sets $(44 \%)$ and cars $(38 \%)$. The level of agreement between preferred toy and toy used in real play is similar in all age groups.

\section{CARS VERSUS DOLLS}

The most frequently mentioned types of toys were cars and dolls. Table III below shows the proportion of children mentioning dolls and cars in reply to one of the first four interview questions. The Table III shows independent shares of individual category items in replies to the answers. Both cars and dolls were among toys that the children most strongly associate with girls or boys.

TABLE III: CARS AND DOLLS IN MENTAL STEREOTYPING

\begin{tabular}{lll}
\hline \hline Toys, plays & Girls & Boys \\
\hline Boys play with cars. & $70.6 \%$ & $67.4 \%$ \\
Girls play with dolls. & $73.2 \%$ & $71.0 \%$ \\
Dolls are inappropriate for boys. & $59.3 \%$ & $54.0 \%$ \\
Cars are inappropriate for girls. & $47.6 \%$ & $41.1 \%$ \\
\hline \hline
\end{tabular}

The degree to which boys and girls associate cars with masculinity and dolls with femininity does not differ. More than $2 / 3$ or nearly $3 / 4$ of girls and boys see cars as toys dominantly played with by boys and dolls as toys played with by girls and approximately one half rejects dolls as toys for boys and cars as toys for girls. Judging by the absence of significant differences we can state that girls and boys share similar gender norms, which define optimal play behavior associated with femininity and masculinity.

The results show that positive association of cars and dolls with the category of gender is relatively strong and appears in both sub-groups with approximately the same frequency. Defining gender categories by negation, i.e. by excluding certain toys, is somewhat weaker, nevertheless it is an operation that can still be considered strong. Negation (as opposed to positive definition) is used more for defining masculinity. Refusal of boys playing with dolls is much stronger than the refusal of girls playing with cars, $x^{2}(1$, $n=455)=49.29, p<0.01$.

In the research sample there were $25 \%$ of girls and $30 \%$ of boys who, when defining femininity (i.e. when replying to the question asking about with what toys do girls play with and with what toys are they not supposed to play with) used mutually exclusive answers dolls and cars. Cars and dolls were mentioned concurrently when defining masculinity by $35 \%$ of girls and $29 \%$ of boys. If we focus on the overlapping of both answers, we will find out that $39.4 \%$ of girls and $42.4 \%$ of boys stated that dolls are toys for girls, but not for boys, and $39.8 \%$ of girls and $33.9 \%$ of boys stated that cars are toys for boys, but not for girls. Approximately between $1 / 3$ and $1 / 2$ of children therefore puts dolls and cars in mutual opposition. Based on this, we can deduce that dolls and cars delimit the borderline between genders, and children therefore use these toys for the most precise and efficient definition of masculinity and femininity.

The correlations between age and the choice of cars/dolls suggest that both girls and boys become more critical to boys playing with dolls with increasing age. At the same time, boys become more convinced with increasing age that dolls are toys for girls. In groups of older children, refusing dolls as toys for boys and concurrent stressing of dolls as toys for girls is very common - this opinion is shared by up to $2 / 3$ of older children. On the other hand, defining cars as toys inappropriate for girls, but typical for boys was also very frequent, even though slightly less than in the case of dolls (this opinion is shared by approximately one half of older children). In younger groups, positive definition of dolls as girls' toys and cars as boys' toys prevails while negative definition (i.e. refusing of certain toys as toys appropriate for girls or boys) is not that common. It can be summarized that with higher age, focus on definition by negation becomes stronger, in particular in the case of the definition of masculinity, which is accompanied by request that boys do not play with dolls.

During observation, the way how children play with cars and with dolls differ a lot. We can consider several aspects of plays: social-communication, motor-kinetic and cognitive. With regard to social skills and communication, playing with cars is much more focused on competition (i.e. whose car is faster), while playing with dolls is focused on conversational communication between children or on "workaday" communication between child and the doll. Dominant communicative style corresponds with constructive type of play with cars and pretend play with dolls [7]. With regard to motor and kinetic skills, both toys can support both the locomotion of whole body and of the fingers. The proportion depends on the structure of certain play (f.e. on one hand dressing the doll and repairing the car, on the other hand riding with doll-stroller or with car). In observed play activities, the majority of girls use dolls in both ways, but majority of boys prefer the great-locomotion way of playing with cars. With regard to cognitive skills, playing with cars is often connected with discussions on many technical or geographical details. Children present new information to each other (which is implicit part of competition). Dolls support the "soft" verbal skills because children describe what they see and do in many different words, including emotions as the important part and topic of communication.

\section{DISCUSSION}

Analyses confirmed that preschool children approach toys based on gender dichotomy. It is in correspondence with the results of previous research [3], [5]. Even though children have experience with a broad range of toys, in attributing toys to gender categories preschool children stay within more narrow defined limits. They expect girls to play mainly with dolls, animals or figures. This opinion is shared by $78 \%$ of girls and $70 \%$ of boys. This is in agreement with toys dominantly preferred by girls - dolls, animals and figures were mentioned as personal favorite toys by $67 \%$ of girls (if we use all the mentioned preferred choices, the percentage reaches $100 \%$ ). However, the connection with real choice is weaker - the two mentioned types of toys were used as the main toy in free play by only $36 \%$ of girls (when taking into account three most frequent play activities, the percentage 
increases to $68 \%$ ).

Boys are expected to play with cars and construction sets. This opinion is shared by $75 \%$ of girls and $71 \%$ of boys. These toys are preferred by $62 \%$ of boys (when taking into account all preferred choices, the percentage increases to 93\%) and during observation of free play they were the dominant play activity in $77 \%$ of boys (when taking into account all observed play activities in the group, they were preferred by full 100\%). There is an agreement between gender concepts relating to toys, personal toy preferences and toys used in real play in the case of boys, but the agreement is less strong in the case of girls. Among girls, toys observed during real play show greater variability in comparison to the expressed personal preferences and also to gender stereotypes.

Dolls and figures on the one side and cars and construction sets on the other side differ in the cognitive processes involved in playing activity. With regard to mathematical ability, we can argue that toys preferred by and associated with boys support this area more than "girls' toys". Especially visualization and construction are more integrative part of play with cars and building sets. However, our research did not examine primarily this area thus the finding is not based on data properly. The area should be described exclusively.

Existing research studies agree that gender schemas influence cognitive processing of information and adopting of attitudes [5], [10]. However, the studies do not agree on the impact of gender on behavioral manifestations. Some authors believe that increased mental flexibility leads to greater diversity in behavior [13], but others claim that behavior may stay unaffected by increased flexibility [11]. Our findings suggest that the relationship between gender schemas, preferences and real choices is controlled by different mechanisms in girls and in boys. Both groups share similar stereotypes about what toys are typical for each gender, and these stereotypes are in agreement, even though to a lesser degree, with their personal toy preferences. However, when observing children during free play, higher level of agreement with gender stereotypes was observed in boys (in comparison to expressed personal preferences). In girls, on the other hand, a significantly lower level of agreement both with gender stereotypes and personal preferences was found.

This means that during real play girls use also toys with they do not consider typical for their gender, even though in their expressed preferences they follow their gender stereotypes. Boys, on the other hand, dominantly play with gender typical toys during free play, even if they express preference of other toys. These findings suggest that there exists an indirect relationship between cognitive and behavioral aspects of gender. However, the findings can also be influenced by unbalanced or limited choice of toys in nursery schools and also by the tendency of children to engage in group activities, during which they adapt to the choice of toys by their peers. In natural conditions it was not possible to differentiate the impacts of these factors (on the other hand, laboratory research has other disadvantages).

A surprising finding is the fact that the structure of results was similar in different age groups. Even though the variability of preferred toys and of toys chosen in real play increases with increasing age, the ratio between all three categories (i.e. attributing toys to gender categories, personal preference and personal choice) remained roughly the same in all studied age groups. Existing studies show that preschool children adhere to very rigid gender schemas at least until the age of 5. Later, the flexibility slowly increases reaching its peak at the age of 10-12 years [6], [11], [12]. The signs of increasing flexibility should be weaker gender dichotomy of toys and weaker adherence to stereotypes in the child's behavior. However, the results of our study focusing on children between 3 and 7 years of age do not confirm a clear trend of increasing flexibility.

Existing studies concur that requirements concerning masculinity are usually more narrowly defined and more rigid than requirements concerning femininity [3]. This can be confirmed also by our findings. Stereotypes regarding boys' toys are relatively narrowly defined, both in their positive and negative definition. Children strictly insist that certain toys are not appropriate for boys. Therefore, the borderline separating masculinity from femininity is guarded more strictly. This imaginary borderline is delimited by dolls and cars, which a large proportion of children view as toys defining boys and girls and which are frequently mentioned in mutual opposition (i.e. cars are appropriate for boys and dolls are appropriate for girls). According to children, dolls are in stronger contradiction with masculinity than cars are with femininity - this conviction is strongest among five and six year old girls.

Paradoxically, both higher variability and higher rigidity of gender schemas was observed in girls. Girls play with a wider range of toys, but they at the same time also more frequently agree on what toys do both groups play with and what toys are in contradiction with femininity or masculinity. This finding is partially in disagreement with findings of other studies, which usually observed not only broader range of behavioral manifestations in girls, but also less strict gender schemas and earlier development of flexibility [3]-[5]. In our research, girls expressed more narrowly defined stereotypes, in particular in negative definitions of boys' toys (dolls are not appropriate toys for boys). This confirms findings from other research studies according to which the definition of masculinity tends to be stricter, but the stricter definition is more often asserted by girls than boys. On the other hand, as far as the femininity concept is concerned, girls tent to be less strict and a higher proportion of girls prefers and plays with toys associated with boys (cars and construction sets were mentioned as favorite toys by $18 \%$ of girls and $33 \%$ of girls played with these toys in real situations). Among boys, the preference and choice of toys associated with femininity (dolls, animals or figures) was lower - these toys were mentioned among three favored toys by $10 \%$ of boys and there were chosen during the play by the same percentage.

Important group of toys are the constructions. Boys engage in these activities according to $18 \%$ of boys and according to $19 \%$ of girls. These types of toys are also played with by girls, even though to a lesser degree $-3 \%$ of both boys and girls mentioned these types of toys as a dominant girl's play (putting these toys at the 6th position according to frequency). 
At the same time, however, both $6 \%$ of girls and boys described this type of activity as inappropriate for girls. Out of the total number of 883 answers in which children identified some toys as inappropriate for girls, $8 \%$ mentioned specifically Lego. Wolfgang [8] shows that toys as Lego establish better background for later success in mathematics.

In opposed to foreign studies, the results of our research do not confirm generally higher flexibility in the application of gender schemas by girls (flexibility is higher in the case of femininity, but not in the case of masculinity). The explanation for these findings could be the specific form of relationship between socialization and gender socialization in post-communist countries. Over the past twenty years, the upbringing and education in families and in schools rapidly liberalized. However, the patterns of gender socialization preserved their differences, i.e. girls are encouraged to be passive, relational, while boys are encouraged to be independent, active. The current approach to children's upbringing consisting in removing as many restrictions as possible produces different outcomes in combination with gender stereotypes - in the case of boys it leads to generally more relaxed attitudes, while in the case of girls it supports following of external influences and expectations. This might be the reason why girls more strictly follow and control compliance with gender roles by themselves and by others. This is just a hypothesis that has not been proven yet for preschool children. However, for early primary school age, we already have first partial studies available suggesting that the Czech boys currently follow generally looser patterns, which has negative impacts on their study performance in the educational environment that is much less structured than it was in the past.

\section{CONCLUSION}

We can conclude that our research confirmed that preschool children understand toys as gendered. Gender polarization of toys leads, although not directly, yet still quite strongly, to the focus on certain specific play activities, which, when repeated over a longer period of time help to train specific abilities. These abilities are developed on the level of knowledge and skills, but also on a deeper level of dispositions and aptitudes. Changes can occur even on the physiognomic and physiologic level - the child may dominantly develop specific muscle groups and specific brain centers or connections. As an example, technical toy sets may be mentioned, which are more frequently associated with boys. Toy sets help to develop among other visual-spatial skills [3], [10] in which significant gender differences can be observed starting form higher school age. Child development is thus supported along a certain direction and the cumulative effect usually further strengthens this development in the following phases of the child's development. A child that engages often in a certain type of activity not only acquires objective skills, but also subjective feeling of competency, which strengthens the child's motivation and interest in the given area. At the same time, children are supported in these activities also by adults, especially if the activity in which the child engages is in agreement with the parents' and the teacher's gender concepts.
In order to ensure comprehensive development of a child's personality it is therefore important to actively support the use of the broadest possible range of toys.

\section{REFERENCES}

[1] F. P. Hughes, Children, Play, and Development, Thousand Oaks: SAGE Publications, 2010.

[2] E. E. Maccoby, "Gender and relationships: a developmental account," American Psychologist, vol. 45, no. 4, pp. 513-520, 1990.W. S.

[3] B. Francis, "Gender, toys and learning," Oxford Review of Education, vol. 36, no. 3, pp. 325-344, 2010.

[4] N. K. Freeman, "Preschoolers' perceptions of gender appropriate toys and their parents' beliefs about genderized behaviors: Miscommunication, mixed messages, or hidden truths?" Early Childhood Education Journal, vol. 34, no. 5, pp. 357-366, 2007.

[5] C. L. Martin, L. Eisenbud, and H. Rose. "Children's gender-based reasoning about toys," Child Development, vol. 66, pp. 1453-1471, 1995.

[6] A. Nelson, "Gendered toy play as mediated action," Psychological Science and Education, vol. 2, pp. 71-77, 2011.

[7] V. Gmitrova, M. Podhajecka, and J. Gmitrov, "Children's play preferences: implications for the preschool education," Early Child Development and Care, vol. 179, no. 3, pp. 339-351, 2009.

[8] C. Wolfgang, L. Stannard, and I. Jones, "Advanced constructional play with LEGOs among preschoolers as a predictor of later school achievement in mathematics," Early Child Development and Care, vol. 173, no. 5, pp. 467-475, 2003.

[9] Barnett, "Preschool education and its lasting effects: research and policy implications," Great Lakes Center for Education Research and Practice, 2008.

[10] K. K. Powlishta, "Gender as a social category: intergroup processes and gender-role development, " The Development of the Social Self, pp. 103-133, 2004.

[11] R. Banse, B. Gawronski, C. Rebetez, H. Gutt, and J. B. Morton, "The development of spontaneous gender stereotyping in childhood: relations to stereotype knowledge and stereotype flexibility," Developmental Science, vol. 13, no. 2, pp. 298-306, 2010.

[12] C. L. Martin and D. Ruble, "Children search for gender cues: cognitive perspectives on gender development," Current Directions in Psychological Science, vol. 13, no. 2, pp. 67-70, 2004.

[13] R. Banerjee and V. Lintern, "Boys will be boys: the effect of social evaluation concerns on gender-typing," Social Development, vol. 9, no. 3, pp. 397-408, 2000.

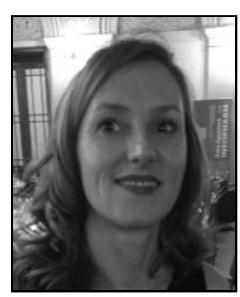

Irena Smetackova was born in Prague, Czech Republic, in 1976. She gained master degrees in sociology, psychology and pedagogy and doctoral degree in pedagogical psychology. Since university studies, she has works as a researcher and psychologist.

Last ten years she is an assistant professor at Department of Psychology, Faculty of Education, Charles University, Prague. Her research interests include mainly gender socialization and gender equality in education. In this field she has conducted both scientific and practice-targeted projects. Among her biggest research projects belongs "Gender Aspects of Transitions between School Levels", "Sexual harassment at Czech Universities", "Connection between gender schemas and social structure of peer groups", "Legitimization of Stereotypes in Czech Republic" etc. She published more than 25 articles and chapters in books, mainly in Czech language. The list of her foreign language publications includes: Sexual and Gender Motivated Harassment at Czech Universities: Incidence, Perception and Implications for Sexual Ethics. (Oxford: Inter-Disciplinary Press, 2010) or Transformation des politiques d'équité en période post-communiste. In Les politiques d'éducation prioritaire suédoise en periode de décentralisation et d'individualisation. République tchéque. (Lyon: Institut National de Recherche Pédagogique, 2008).

Dr. Smetackova is a member of Czech Government Council for Equal Opportunities for Women and Men and a member of board for Equal Opportunities for Women and Men, Ministry of Education, Czech Republic. 